Western University Scholarship@Western

Electrical and Computer Engineering Publications Electrical and Computer Engineering Department

$1-2007$

\title{
Managing the Business of Software Product Line: An Empirical Investigation of Key Business Factors
}

Faheem Ahmed

Thompson River University, fahmed@uwo.ca

Luiz Fernando Capretz

University of Western Ontario, lcapretz@uwo.ca

Follow this and additional works at: https://ir.lib.uwo.ca/electricalpub

Part of the Software Engineering Commons

Citation of this paper:

$@$ article $\{$ DBLP:journals/infsof $/$ AhmedC07, author $=\{$ Faheem Ahmed and Luiz Fernando Capretz $\}$, title $=\{$ Managing the business of software product line: An empirical investigation of key business factors $\}$, journal $=\{$ Information $\{\backslash \&\}$ Software Technology $\}$, volume $=\{49\}$, number $=\{2\}$, year $=\{2007\}$, pages $=\{194-208\}$, ee $=\{$ http: $/ /$ dx.doi.org $/ 10.1016 /$ j.infsof.2006.05.004 $\}$, bibsource $=$ \{DBLP, http://dblp.uni-trier.de $\}$ \} 


\title{
Managing the Business of Software Product Line: An Empirical Investigation of Key Business Factors
}

\author{
Faheem Ahmed, Luiz Fernando Capretz \\ Department of Electrical \& Computer Engineering \\ University of Western Ontario, London, Ontario, Canada, N6A 5B9 \\ fahmed@engga.uwo.ca, lcapretz@eng.uwo.ca
}

\begin{abstract}
Business has been highlighted as a one of the critical dimensions of software product line engineering. This paper's main contribution is to increase the understanding of the influence of key business factors by showing empirically that they play an imperative role in managing a successful software product line. A quantitative survey of software organizations currently involved in the business of developing software product lines over a wide range of operations, including consumer electronics, telecommunications, avionics, and information technology, was designed to test the conceptual model and hypotheses of the study. This is the first study to demonstrate the relationships between the key business factors and software product lines. The results provide evidence that organizations in the business of software product line development have to cope with multiple key business factors to improve the overall performance of the business, in addition to their efforts in software development. The conclusions of this investigation reinforce current perceptions of the significance of key business factors in successful software product line business.
\end{abstract}

\section{INTRODUCTION}

Software organizations are improving business operations such as technology, administration, and product development process in order to capture a major portion of the market share to be profitable. One of their major concerns is the effective utilization of software assets, thus reducing considerably the development time and cost of software products. Many organizations that deal in wide areas of operation, from consumer electronics, telecommunications, and avionics to information technology, are using software product lines practice, because it deals with effective utilization of software assets. Software product lines are promising, with the potential to substantially increase the productivity of the software development process and emerging as an attractive phenomenon within many organizations that deal with the software development. A software product line is a comprehensive model for an organization building applications based on common architecture and core assets [47]. Clements [11] defines the term "software product line" as a set of software-intensive systems sharing a common, managed set of features that satisfy the specific needs of a particular market segment or mission, and that are developed from a common set of core assets in a prescribed way. Other terminologies for "software product line" that have been widely used in Europe include "product families", "product population", and "system families". In the overview of a European project, "Engineering Software Architecture, Processes and Platforms for System-Families" [21], a system family is defined as a group of systems sharing a common, managed set of features which satisfy the core needs of a scoped domain. Ommering [37] introduced the term "product population", which is a collection of related systems based on similar technology but with many differences among them. The Software Engineering Institute (SEI) proposes the Product Line Technical Probe (PLTP) [12], aims at discovering the ability of an organization to adapt and succeed with the software product line approach. PLTP is based on the framework for software product line practice, which divides the overall software product line process into set of three essential activities of product development, core asset development, and management. The economic potential of software product lines has long been recognized in software industry [8] [46].

Today, all businesses are experiencing greater competition, and customers' expectations continuously increase as technology advances at an unprecedented rate of growth. The rapid and continual changes common to the present business environment not only affect business itself but also have a profound impact on production. Software is perhaps the most crucial piece of a business entity in this modern marketplace, where important decisions need to be made immediately. Organizations that fail to respond appropriately do not survive longer. The keys to success are in continuously monitoring customers and the competitors 
and in making improvement plans based on observations and measurements. Business is perhaps the most crucial factor in a software product line, mainly due to the necessities of long-term strategic planning, initial investment, longer payback period and retaining the market presence. The main objective of this work is to conduct a comprehensive empirical investigation that in particular delineates the interrelationships among the business factors and software product line performance.

\section{A. Software Product Line and Business Factors: Related Work}

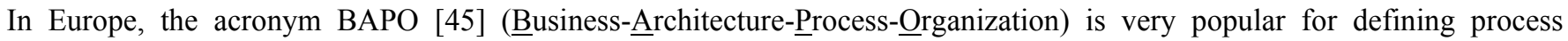
concerns associated with software product lines. The "Business" in BAPO is considered critical because it deals with the way the products resulting from software product lines make profits. Bayer et al [3] at Fraunhofer Institute of Experimental Software Engineering (IESE) develop a methodology called PuLSE (Product Line Software Engineering) for the purpose of enabling the conception and deployment of software product lines within a large variety of enterprise contexts. PuLSE-Eco is a part of PuLSE methodology, deals with defining the scope of software product lines in terms of business factor. Pulse-Eco identifies various activities, which directly address the business needs of software product lines such as: system information, stakeholder information, business objectives and benefit analysis. van der Linden et al. [45] identifies some main factors in evaluating the business dimension of software product line such as: identity, vision, objectives and strategic planning. They classified the business maturity of software product line into five levels in the ascending order: reactive, awareness, extrapolate, proactive and strategic. Clements and Northrop [12] highlight customer interface management, market analysis, funding, and business case engineering as important activities from the perspectives of managing the business of software product line. Kang et al. [29] present a marketing plan for software product lines that includes market analysis and marketing strategy. The market analysis covers need analysis, user profiling, business opportunity, time to market and product pricing. The marketing strategy discusses product delivery methods. Toft et al. [44] propose "Owen molecule model" consisting of three dimensions of social, technology and business. The business dimension deals with setting up business goals and analyzing commercial environment. Fritsch and Hahn [23] introduce Product Line Potential Analysis (PLPA), which aims at examining the product line potential of a business unit through discussions with managers of the business unit because in their opinion they know the market requirements, product information and business goals of the organization. Schmid and Verlage [40] discuss the successful case study of setting up software product line at Market Maker and highlights market and competitors analysis, vision of potential market segment, and products as significantly important activities. Ebert and Smouts [20] weight marketing as one of the major external success factors of product line approach and further concluded that forecasting, ways to influence market, strong coordination between marketing and engineering activities, are required for gaining benefits from product line approach. The summary of the related work presented in this sub-section exposes some key business factors such as strategic planning, innovation, market orientation, business vision, order of entry to the market, and customer orientation. We used these key business factors in addition to some others as a set of independent variables in the empirical investigation presented in this paper in order to construct the research model of our investigation.

\section{Conceptual Model, Research Questions And Hypotheses}

Davenport [18] describes a business process as a structured set of activities designed to produce a specific outcome. AguilarSav'en [1] asserts that a business process is the combination of a set of activities within a structured enterprise. Figure 1 depicts the research model to be empirically tested in this study. The model derives its theoretical foundations by combining prior research in software engineering, software product lines, business literature, and operational and technical management. The model includes seven key business factors: strategic planning, order of entry to the market, brand name strategy, market orientation, relationships management, business vision, and innovation, as well as a dependent variable: the business performance of software product lines. In the rest of this paper the term "key business factors" refers to those seven independent variables, which are used in this research model. The objectives of this study is to investigate empirically the answers of the following research questions:

RQ-1: Does key business factors have an impact on overall performance of software product lines?

RQ-2: What is the role of strategic planning in software product line performance?

RQ-3: What is the effect of marketing strategy in software product line performance?

The main objective of the research model is to analyze the association among various key business factors and to study the relationships between them and the business performance of software product lines. It is important to note here that although the associations of key business factors, such as strategic planning, order of entry to the market, market orientation, and relationship management have been studied by various researchers in management and the business community, but this study is first of its 
kind in the context of software product lines at the best of our knowledge. This study provides an opportunity to analyze the association among the key business factors in the business of software product lines and shows their impact on the overall business performance of an organization dealing with software product lines. In order to empirically investigate the research questions we hypothesize the following:

H1: Strategic planning for software product lines is positively associated with business vision.

$\mathrm{H} 2$ : Business vision is positively associated with innovation.

H3: The business performance of an organization's software product line is positively associated with strategic planning.

H4: The business performance of an organization's software product line is positively associated with relationship management.

H5: Strategic planning is positively associated with market orientation.

H6: The business performance of an organization's software product line is positively associated with market orientation.

H7: The business performance of an organization's software product line is positively associated with brand name strategy.

H8: Order of entry to the market is positively associated with market orientation.

H9: Brand name strategy is positively associated with market orientation.

The theoretical foundations for the hypotheses of this study is discussed in the next sub-sections by elaborating the key business factors in detail along with their aspects related to software product lines.

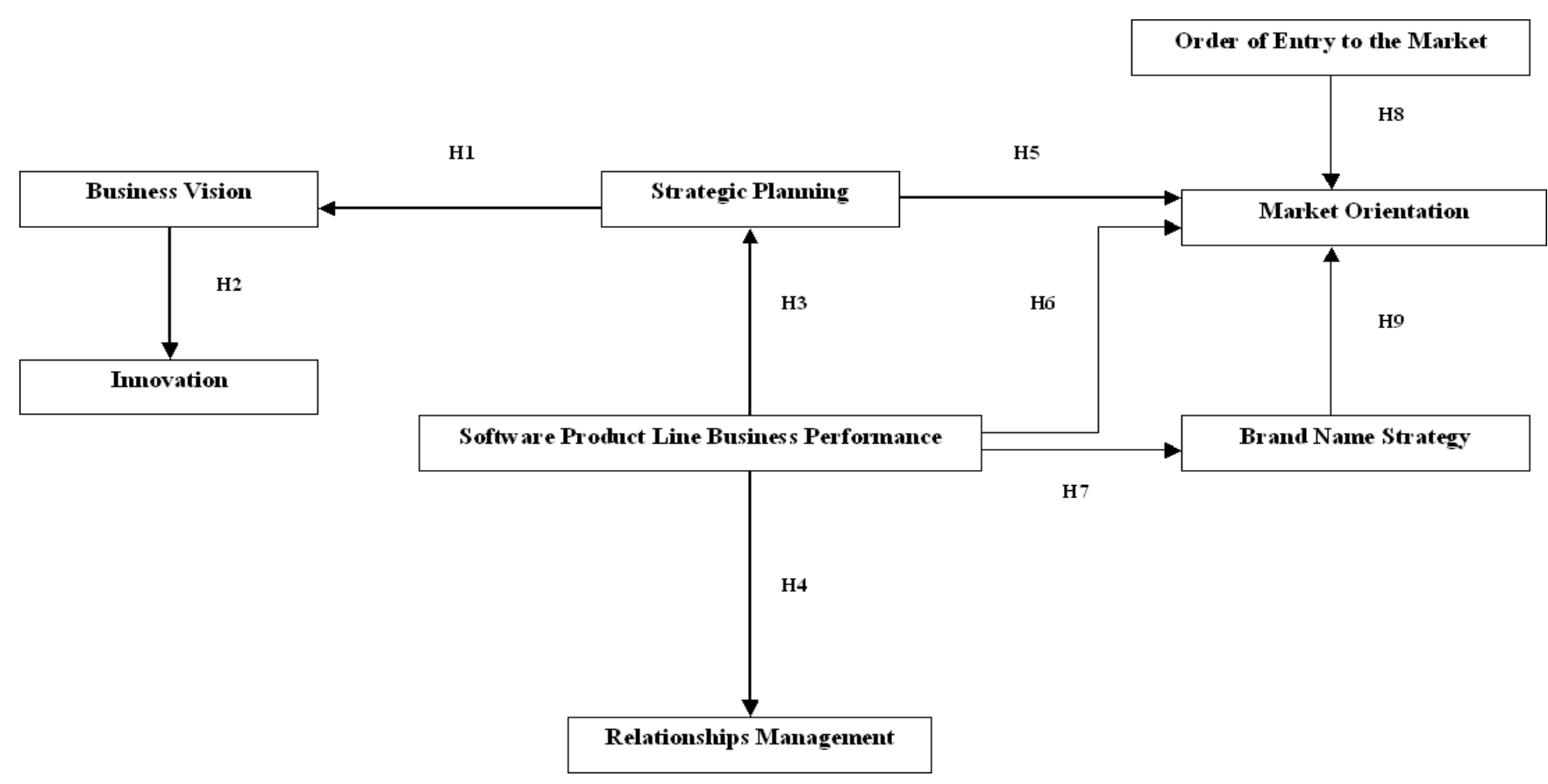

Figure 1: Conceptual Research Model

\section{A. Strategic Planning}

Strategic plans are the focus of an organization's endeavors to accomplish the desired level of achievement in a particular area. Strategic planning starts with elaborating strategic objectives. Harrison [24] asserted that objectives indicate what management expects to accomplish, while planning sets forth how, when, where and by whom the objectives will be attained. 
Sutton [43] describes strategic planning as a mechanism with which an organization collects and evaluates information about its own operations and its relationship to its environment, generates projections about future changes in that environment, and sets organizational goals based on those projections, which then serve as both a blueprint for change and a measure of progress. Thus, according to Sutton, strategic plans define what is to be achieved over a period of time. Strategic planning is a continuous process within an organization; it determines business goals, evaluates the obstacles and defines approaches to deal with those obstacles. It outlines definite tasks for individuals, groups, and the entire organization that are needed to accomplish these goals. It is important to understand the difference between vision and strategic planning. Vision is the overall statement of the company's desired future financial position and business excellence, whereas strategic planning defines specific activities to be carried out in order to achieve the goals of a business. Niemelä [35] highlighted eight different strategies for adopting software product lines in an organization: minimizing risk, extending market share, maximizing end-user satisfaction, balancing cost and potential, balancing cost, customer satisfaction and potential, and maximizing potential. Niemelä [35] further concluded that a company has to evaluate the current status of their business, architecture, process, and organizational issues before making a decision about choosing one strategy out of those in order to achieve desired benefits. The software product line process needs resources, which must be delegated in strategic plans. Strategic planning must clearly outline what is to be developed from the software product line in order to gain competitive advantages and capture market segments to achieve strategic targets. Strategic plans are required to maintain organizational wide efforts to identify and exploit attractive long-range business opportunities by having the software product line in practice.

\section{B. Order of Entry to the Market}

There are three observable categories in a firm's order of entry to the market: pioneers, early followers, and late movers [2] [38]. The benefits of being the first in the market have long been recognized in the business sector; pioneers often gain a sustainable competitive advantage over followers, because, initially, they are the only solution-providers in a particular market segment. Thus, they usually capture a bigger portion of the market because they were first. It becomes very difficult for successors to gain a share of the market segment, especially in the case of software, where migration to other software is relatively uncommon. The timing for technology-based products entering the market is even more critical for the profitability and competitive position of an organization. The right product at the right time has a high potential of success. De Castro and Chrisman [19] concluded that a pioneer might also benefit from advantages in technological factors when it is able to develop innovative products or processes and those innovations exclusive, or at least gain a temporal advantage that keeps the organization one step ahead of its followers. Order of market entry is perceived as a crucial business decision, with a longlasting and profound impact on the performance of an organization in capturing and retaining the market. Appropriate timing to launch a software product into the market is even more essential for software development organizations. Timing is essential in launching a new product from the software product line in order to capture major shares of the market. The order of entry to the market depicts the delivery schedule for the software product family and provides guidelines to developers about development schedules.

\section{Brand Name Strategy}

Organizations consider brand name a crucial catalyst of business success. A brand is regarded as both a promise of quality to customers and a point of comparison with other products or services. Bennett [4] defined brand as a name, term, sign, symbol, design, or any combination of these concepts that is used to identify the goods and services of a seller. Brand name products generally have high potential for increasing an organization's business. Branded product serve, as an interface between customers and the organization, and loyalty to a brand is a kind of word-of-mouth advertisement from customers. Brand name strategy affects customers' decision-making processes in choosing a particular product. Bergstrom [5] observed that in the proliferation of competitors and products that are easily duplicated or replaceable, brands become an important means of simplifying the decision-making process for buyers or users. Well-established brands provide a reference point for business growth and assist in directing an organization's future development. A name brand heavily influences decisions about new product development. The product line business is even more inclined towards a brand name strategy, because it envisages the business to grow with a stream of products having commonality and variability. Brand name strategy has also been successfully adopted in software development. Many successful brands in software, such as Windows ${ }^{\circledR}$, AutoCAD ${ }^{\circledR}$, and MATLAB $^{\circledR}$, successfully retain a significant number of customers, thus capturing a major portion of the market segment. But currently there is gab between software product line engineering and brand name strategy; many different products not originating from one software product line can be plugged under one marketed product line. Windows ${ }^{\circledR}$ is a working example of this scenario. Despite this fact there are successful cases that are using brand name strategy in software product lines concept. The product line of Symbian operating system for mobile phones is an example of this scenario. Long range of products under this brand name is currently successfully installed in the handsets of Nokia, Sony Ericsson, Samsung and Panasonic etc. Jaasksi [25] presented the 
case study of developing software product line of mobile browsers under the brand name of "Nokia Mobile Browser" at Nokia is also an example of current use of brand name strategy in software product lines.

\section{Market Orientation}

The concept of market orientation provides an advantage over competitors by identifying what customers' want, and then offering products that are different and superior to those offered by competitors. Market orientation deals with the acquisition, sharing, interpretation, and use of information about customers and competitors, both of which have a significant impact on the performance of the business. Kohli and Jaworski [32] propose a formal definition of market orientation, as "the organizationwide generation of market intelligence pertaining to current and future customer needs, dissemination of that intelligence across departments, and organisation-wide responsiveness to it." Conversely, Narver and Slater [34] define market orientation as "the organization culture that most effectively and efficiently creates the necessary behaviors for the creation of superior value for buyers and, thus, superior performance for the business." According to these definitions, market orientation consists of three dimensions: customer orientation, competitor orientation, and inter-functional coordination. Market orientation is not only a first-time activity, such as the launching of a new product, but it is a continuous process of monitoring customers, competitors, and market trends. Birk et al. [6] defines market orientation in context of software product lines as whether the organization targets a specific market segment without a specific customer in mind or addresses individual customer projects. The software product line deals with developing a considerable number of products to capture various market segments, thus providing justification for a product line. Market orientation provides imperative information about the concerns and requirements of customers, which needs to be accommodated in the successive products from a product line. Pulse-Eco [31] illustrates various activities associated with market orientation for successful adoption of software product lines concept in an organization. It considers collecting and analyzing stakeholders' information is helpful in defining the product line scope.

\section{E. Relationships Management}

The effective management of the buyer-seller relationship is highly critical for successful businesses. Wilson [49] observed that relationships management is concerned with the development and maintenance of close, long-term, and mutually beneficial and satisfying relationships between individuals or organizations-relationships that are based on trust and collaboration. Crosby et al. [17] considered relationships management as the extent to which parties have an orientation or behavioral tendency to actively cultivate and maintain close working relationships. Organizations that have established close relationships with their customers are generally more successful in maintaining profitable businesses. Some contributing factors to good relationships management are the management of customer information, customer profiling, customer support and services, promotional strategies, channel management, and organizational behavior. Business success is highly dependent on the extent to which customers are satisfied with an organization's product and services, as well as how they win the loyalty of customers by improving their relationships management. Relationships management plays a significant role in successful software product line development. Excellent working relationships with customers allow the developers to improve the performance and functionalities of successive products from the product line by better understanding the customers' requirements and learning about market trends from the end users.

\section{F. Business Vision}

By definition, "vision" portrays a mental picture of a preferred future state. The term "business vision" entails a description of an organization several years in the future. Business vision is not a dream or set of hopes; it is a commitment to reach a specific goal. Business vision is based on reality and the current state of the organization, but it is focused on the future. It allows the organization to prepare action plans for introducing changes and improvements in current practices to reach the future objectives. In practice, business vision is a statement prepared by top management and communicated to all members of the organization. The top managers prepare the business vision after analyzing the organization's current situation and its impact on the external environment. The statement includes the identification of a desired future and a well-established connection between the present state and the future. Overall, the business vision serves to link an organization's experiences and knowledge of the past and the present with decisions about the future. A successful business vision plan requires that all employees within an organization participate and clearly understand the vision statement. The main objectives are to consider business vision as reference point and to realistically ask the questions: "Where are we going?" and "Where do we have to go?" Then, the organization prepares actions plans to answer the query, "How can we reach to that future state?" The software product line can play a significant role in the business vision because it tends to produce long-term benefits to the organization. A clear statement about business vision will guide practitioners of the software product line to establish a production facility in order to meet the future goals of the organization. By including the software product line in the business vision, an organization can stream line its 
business operations in order to capitalize on its market audience for profitable venture. Wijnstra [48] concluded that a complete business roadmap is needed to describe what is expected from the software product lines in the years to come and how it will fit in the plan for the release of new products.

\section{G. Innovation}

The key to a successful business in today's competitive environment is innovation. Organizations are continuously adopting innovations in major areas of business operations, such as technology, administration, and production processes. Innovation is regarded as a by-product of research and development. Continuous research in attempting to understand a problem and discover its possible solution leads to innovation. Martensen and Dahlgaard [33] maintained that an innovative strategy should be closely linked to the company's vision and overall business strategy, as well as be based on comprehensive and relevant information, both from inside the company and from the market. Innovation and continuous improvements in processes and products illustrate the capability of an organization to be creative and to be pioneers in product development. Organizations with designs on capturing a major share of the market, in order to increase business, spend heavily on research and development. Business objectives influence research and development efforts because the order of a product's entry into the market can make a significant difference in achieving strategic goals. Thus, research and development in technology, administration, processes, and product produce enduring results. The software product line is a relatively new concept, and a lot of research and development in process definition and development methodology is in progress. The research is occurring at various levels of industry and academia to improve the process and product development activity of the software product line for the successful industrialization of this valuable concept. Organizations are trying to institutionalize this concept in innovative ways to make the most effective use of it. Böckle [7] highlighted some measures of innovation management in software product line organizations, which include a planned innovation process, clear roles and responsibilities definition for innovation management structure. Böckle [7] further stressed that the evolution of the product portfolio, platform, variability model, and reference architecture shall be planned with further innovations in mind.

\section{RESEARCH Method}

\section{A. Variables and Data Collection Procedure}

Software organizations covering a wide range of operations, such as consumer electronics, telecommunication, avionics, automobiles, and information technology, and having been involved in the business of software product lines for more than five years were the target population for this study. Figure 2 illustrates the industry classification of the population. We approached 11 organizations and out of them, 8 organizations agreed to participate in the study with a mutual understanding of keeping the names of the organizations confidential. The one organization out of three, who did not agree to participate in this study, was not able to meet our initial criteria set of five years of experience in software product line development. The other two declined our request due to their internal policy. The participating organizations are North American and European multinational companies. The organizations differed in size and range from medium to large-scale. We assume that the a medium scale organization has number of employees around 2000 to 3000, whereas a large-scale organization has more then 3000 employees. It is important to note here that the size of the organization in terms of number of employees is based on total number of employees in the organization working in various departments.

The questionnaire presented in Appendix-I was used to serve as a source of first contact in learning the extent to which the key business factors were practiced within each organization dealing in the software product line business and their perceived level of business performance. We used 35 separate items to measure the performance of key business factors. We used eight items to measure each organization's performance in the software product line business. We requested the organizations under study to distribute the questionnaire within various departments. The respondents, on average, had been associated with the organizations for the last five years. The minimum qualification of respondents was an undergraduate university degree and the maximum was a Ph.D. degree. The respondents generally belonged to middle and senior management and development categories; they either had roles in making policies or implementing organizational strategies from top to bottom. We received a minimum of three and a maximum of seven responses from each organization. The total respondents were 44 altogether. The lower sample size in terms of number of organizations and respondents has a potential threat to the external validity of this study. The one major reason behind lower number of participating organizations is our initial criteria set of five years of experience in software product line development. There are not many organizations having the required level of experience in the business of software product line in particular due to relative young age of this concept. The reason behind choosing the five years experience in software product line business, as a criteria set is the characteristics of long-term payback period of software product line. In order to enhance the external validity we intend to ensure that organizations have started enjoying the benefits of software product line in terms of pay back. The number of respondents from organizations was beyond our control as we 
requested at the organizational level to distribute the survey and provide us feedback.

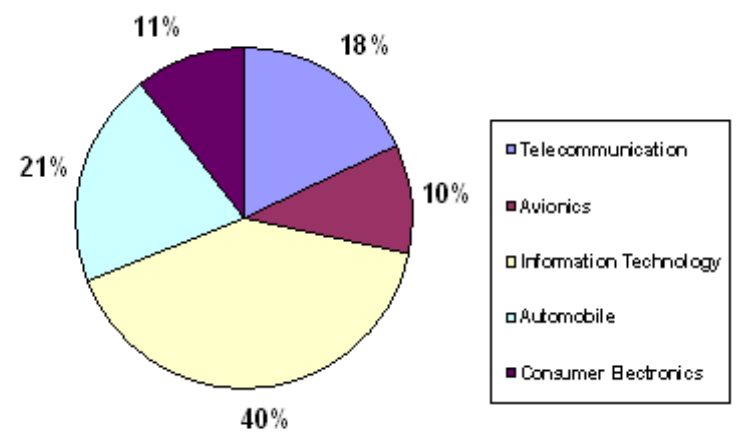

Figure 2: Industry classification of data population

Table-I

Major Sources of Data

\begin{tabular}{|l|l|l|}
\hline Key Business Factor & Sources of Data & Department or Actor Title \\
\hline Market Orientation & Market Analysis, Competitors Information Survey, Strategic & Sales Force, Marketing Strategist, \\
& $\begin{array}{l}\text { Marketing Plans, Sales Mission Statement, Business Model, } \\
\text { Advertising, Strategies, Competition and Buying Patterns, } \\
\text { Sales Forecast, Product Portfolio, Domain Model }\end{array}$ & $\begin{array}{l}\text { Business Analyst } \\
\text { Portfolio Analyst, Domain } \\
\text { Engineer, Software Engineer }\end{array}$ \\
\hline $\begin{array}{l}\text { Relationships } \\
\text { Management }\end{array}$ & $\begin{array}{l}\text { Sales Data, Customer Profiling and History, } \\
\text { Customers Complaint Log, Product Promotions Plans and } \\
\text { Effects, Product Advertising Plans, Public Relations, } \\
\text { Procedures of Sales and Distribution, Customer Inquiries } \\
\text { and Satisfactions Ratio }\end{array}$ & $\begin{array}{l}\text { Customer Relation Officer } \\
\text { Sales Force } \\
\text { Customer Support Representative } \\
\text { Product Developers } \\
\text { Software Requirements Engineer }\end{array}$ \\
\hline $\begin{array}{l}\text { Order of Entry to the } \\
\text { Market }\end{array}$ & $\begin{array}{l}\text { Business Model, Competition and Buying Patterns, Product } \\
\text { Launch Timings, Business Case Evaluation, Sales }\end{array}$ & $\begin{array}{l}\text { Sales Force, Business Analyst } \\
\text { Marketing Strategist, Senior } \\
\text { Projections, Sales Data, Market Trend Analysis, Domain } \\
\text { Management, Production Team } \\
\text { Domain Engineer, Application } \\
\text { Engineer }\end{array}$ \\
\hline $\begin{array}{l}\text { Brand Name } \\
\text { Strategy }\end{array}$ & $\begin{array}{l}\text { Business Model, Brand Strength, Sales and Distribution } \\
\text { Procedures, Competition and Buying Patterns, Brand } \\
\text { Competitors Threat Analysis, Product Portfolio, Domain } \\
\text { Model }\end{array}$ & $\begin{array}{l}\text { Sales Force } \\
\text { Business Analyst } \\
\text { Marketing Strategist } \\
\text { Senior Top Management }\end{array}$ \\
\hline Business Vision & Business Vision Statement & Senior Top Management \\
\hline Strategic Planning & $\begin{array}{l}\text { Strategic Planning Document, Strategic Plans Reviews, } \\
\text { Strategic Planning Change Requests, } \\
\text { Strategic Plans Implementation Guidelines, } \\
\text { Organizational Communications Procedures }\end{array}$ & $\begin{array}{l}\text { Senior Top Management } \\
\text { Middle Management } \\
\text { Supervisory Staff } \\
\text { Product Developers }\end{array}$ \\
\hline Innovation & $\begin{array}{l}\text { Research Plans, Product Innovative Features, } \\
\text { Research Financial Model, Competitors Product Analysis, } \\
\text { Domain Model }\end{array}$ & Research Staff, Senior Top \\
Management, Middle Management \\
\end{tabular}

In this study, we collected data on the key business factors and the perceived level of software product line business performance identified in the research model, shown in Figure 1. In order to measure the extent to which each of the seven key business factors were practiced in organizations dealing with software product line business; we used multi-item, five-points Likert scales that ranged from "strongly disagree" (1) to "strongly agree" (5) for all items associated with each variable. Five items for each variable were designed to collect measures on the extent to which the variable is practiced within each organization. The items for all seven key business factors are labeled sequentially in Appendix-I and are numbered 1 to 35 . We measured the other variable, i.e. software product line business performance for the past five years, with respect to cost and development time reductions, customer satisfaction, market growth, market orientation, and financial strengths based on the multi-item, five-point Likert scale. The items specifically designed for collecting measures for this variable are labeled sequentially and are numbered 1 to 8 in Appendix-I. To the best of our knowledge, this is the first study of its kind within the 
area of software product lines; therefore all items shown in Appendix-I are written specifically for this empirical investigation. The major sources of data, i.e., documents, plans, models and actors were identified after discussions with the organizations in order to reduce the chances of over and under estimation by human judgment in filling questionnaires and to increase the reliability of the approach. Table-I illustrates some of the sources of data and actors involved in acquiring the data of business key factors of an organization but not limited. Respondents were requested to consult the actors and documents mentioned in Table-I before answering the items present in questionnaire. Appendix-II shows the values received on the scales for all the seven factors and software product line performance from the respondents.

\section{B. Reliability and Validity of the Measurement Items}

The two most important aspects of precision in empirical studies are reliability and validity. Reliability refers to the reproducibility of a measurement, whereas validity refers to the agreement between the value of a measurement and its true value. The reliability of the multiple-item measurement scales of the seven key business factors was evaluated by internalconsistency analysis. Internal-consistency analysis was performed using coefficient alpha [15]. Table-II reports the reliability analysis; the coefficient alpha ranges from 0.70 to 0.89 . The literature review of reliability revealed that a reliability coefficient of 0.70 or higher is considered satisfactory [36]. Therefore we determined that all variable items developed for this empirical investigation were reliable. We observed the content validity of the items included in each key business factor, following the general recommendations of Cronbach [16] and Straub [42], by carrying out a comprehensive literature survey to include possible items in the variable scales. We also held discussions with the representatives of the organizations to finalize the proposed independent variables and items included in each variable. Statistical and psychological-testing experts reviewed the proposed scales. We conducted pilot tests, which led to modifications in the variable items, based on the suggestions of respondents, which improved the content validity.

\section{Table-II}

\section{Reliability Analysis (Coefficient Alpha) \& Principal Component Analysis of Variables}

\begin{tabular}{|l|c|c|c|}
\hline \multicolumn{1}{|c|}{ Key Business Factors } & Item No. & Coefficient $\alpha$ & Eigen Value \\
\hline Strategic Planning & $1-5$ & 0.89 & 3.57 \\
\hline Order of Entry to the Market & $6-10$ & 0.80 & 2.98 \\
\hline Brand Name Strategy & $11-15$ & 0.88 & 3.49 \\
\hline Market Orientation & $16-20$ & 0.85 & 3.16 \\
\hline Relationship Management & $21-25$ & 0.71 & 2.38 \\
\hline Business Vision & $26-30$ & 0.70 & 2.50 \\
\hline Innovation & $31-35$ & 0.72 & 2.40 \\
\hline
\end{tabular}

Convergent validity, according to Campbell and Fiske [9], occurs when the scale items in a given construct move in the same direction (for reflective measures) and, thus, highly correlate. The principal component analysis [14] performed and reported for all seven key business factors in Table-II, provide a measure of convergent validity. We used eigen values [28] and scree plots [10] as reference points to observe the construct validity using principal component analysis. In this study, we used eigen-valueone-criterion, also known as Kaiser Criterion [27] [41], which means any component having an eigen vlaue greater then one was retained. Eigen values analysis revealed that five out of seven variables completely formed a single factor, whereas in the case of business vision and innovation, two components are formed. But in both cases the eigen values for the second component are slightly higher then the threshold of 1.0. The scree plots clearly showed a cut-off at the first component. Therefore, the convergent validity can be regarded as sufficient. We used multiple regression analysis to determine the criterion validity of the seven key business factors and software product line business performance. Key business factors were used as predictor variables and software product line business performance was used as a criterion variable. The multiple correlation coefficient observed, was 0.78 . Cohen [13] concluded that a multiple correlation coefficient higher than 0.51 corresponds to a large effect size. Therefore, we observed the criterion validity of the variables to be sufficient. The measurements of reliability and validity analysis showed that the measurement procedures used in this study had the required level of psychometric properties.

\section{Data Analysis Techniques}

We used various statistical analysis techniques and initially divided the data analysis activity into two phases in order to analyze the data and to check the significance of hypotheses H1-H9. Phase-I dealt with normal distribution tests and parametric statistics, whereas Phase-II dealt with Partial Least Square (PLS) technique. We tested for the normal distribution of all the key 
business factors using kurtosis, skewness, and Kolmogorov-Smirnov techniques, and we found the values for all three tests to be within the acceptable range for the normal distribution. We conducted tests for hypotheses H1-H9 using parametric statistics, such as the Pearson correlation coefficient and t-test in Phase-I. All t-test performed were one-tailed. In Phase-II, we used the PLS technique because it helps when complexity, non-normal distribution, low theoretical information, and small sample size are issues [22] [26]. Since small sample size was one of the major limitations in this study, therefore, we used PLS technique to increase the reliability of the results as well. The main reason for small sample size is: not many organizations are dealing in software product lines right now because it is relatively a young concept in the software industry. We made some modification to the data received from respondents before performing statistical analysis. Since all the seven independent variables and the dependent variable's measuring instrument had multiple items, therefore we added their ratings to obtain a composite score for that measure before performing statistical analysis. We received varying number of respondents from different organizations, the minimum numbers of respondents from an organization were three and maximum were seven. The statistical analysis results reported in this paper are based on data received from all the respondents. The statistical calculations were performed using Minitab® 14 software.

\section{ReSults, Discussion AND Limitations}

\section{A. Hypotheses Testing Phase-I}

In order to test hypotheses H1-H9, we examined the Pearson correlation coefficient and t-test between individual independent variables and the dependent variable of the research model shown in Figure 1. The result of the statistical calculations for the Pearson correlation coefficient is reported in Table-III. The Pearson correlation coefficient between strategic planning and business vision was positive $(0.70)$ at $\mathrm{P}<0.01$, and thus provided a justification to accept the $\mathrm{H} 1$ hypothesis. The hypothesis $\mathrm{H} 2$ was rejected based on the Pearson correlation coefficient $(0.27)$ at $\mathrm{P}>0.05$, between business vision and innovation. The correlation coefficient of 0.76 at $\mathrm{P}<0.01$ was observed between the software product line business performance and strategic planning. The positive correlation coefficient of 0.66 at $\mathrm{P}<0.01$ meant that $\mathrm{H} 4$ was accepted. Hypothesis $\mathrm{H} 5$ was accepted after analyzing the Pearson correlation coefficient $(0.65$ at $\mathrm{P}<0.05)$. Similarly hypotheses H6, and H8 were accepted based on similar criteria of positive Pearson correlation coefficients at $\mathrm{P}<0.05$. Hypothesis $\mathrm{H} 7$, based on software product line business performance and brand name strategy, and Hypothesis H9 (brand name strategy and market orientation) were not observed significant at $\mathrm{P}<0.05$, hence they were rejected. Hence, it was observed and is reported here that hypotheses H1, H3, H4, H5, $\mathrm{H} 6$, and $\mathrm{H} 8$ are significant and accepted. The hypotheses $\mathrm{H} 2, \mathrm{H} 7$, and $\mathrm{H} 9$ are rejected.

\section{Table-III \\ Test of Hypothesis H1-H9 Using Pearson Correlation}

\begin{tabular}{|l|l|l|}
\hline Hypothesis & \multicolumn{1}{|c|}{ Research Variable Involved } & \multicolumn{1}{|c|}{$\begin{array}{c}\text { Pearson Correlation } \\
\text { Coefficient }\end{array}$} \\
\hline H1 & Strategic Planning -Business Vision & $0.70^{*}$ \\
\hline H2 & Business Vision - Innovation & $0.27^{* * *}$ \\
\hline H3 & Software Product Line Business Performance - Strategic Planning & $0.76^{*}$ \\
\hline H4 & Software Product Line Business Performance - Relationship Management & $0.66^{*}$ \\
\hline H5 & Strategic Planning - Market Orientation & $0.65^{* *}$ \\
\hline H6 & Software Product Line Business Performance - Market Orientation & $0.63^{*}$ \\
\hline H7 & Software Product Line Business Performance - Brand Name Strategy & $0.27^{* * *}$ \\
\hline H8 & Market Orientation - Order of Entry to the Market & $0.64^{*}$ \\
\hline H9 & Brand Name Strategy - Market Orientation & $0.27^{* * *}$ \\
\hline
\end{tabular}

* Significant at $\mathrm{P}<0.01 \quad * *$ Significant at $\mathrm{P}<0.05 \quad * * *$ Insignificant at $\mathrm{P}>0.05$

\section{B. Hypotheses Testing Phase-II}

In Phase-II of testing the hypotheses, we used the Partial Least Square (PLS) technique to overcome some of the associated limitations and to cross validate with the approach of Phase-I. We used a bootstrapping process to test the hypothesized relationships, i.e., H1-H9, by examining their direction and significance. Figure 3 shows the result of structural tests of the research model, and detailed information is reported in Table-IV. The analysis involved path coefficients $\mathrm{R}^{2}$ and F-test statistics. Hypotheses H1, H3, H4, H5, H6, and H8 showed an F-ratio to be significant at P $<0.05$ and are in the same direction as proposed. Hypotheses H2 (business vision and innovation), H7 (software product line business performance and brand name 
strategy), and H9 (brand name strategy and market orientation) were not observed to be significant with an F-ratio at P $<0.05$. Therefore hypotheses H1, H3, H4, H5, H6, and H8 were accepted, while H2, H7, and H9 were rejected.

Table-IV

Test of Hypothesis H1-H9 Using Partial Least Square

\begin{tabular}{|l|l|l|l|}
\hline Hypothesis & Path Coefficient & $\mathrm{R}^{2}$ & F-Ratio \\
\hline H1 & 1.26 & 0.47 & $38.55 *$ \\
\hline H2 & 0.32 & 0.07 & $3.46 * *$ \\
\hline H3 & 0.61 & 0.58 & $59.54 *$ \\
\hline H4 & 0.71 & 0.44 & $33.43 *$ \\
\hline H5 & 0.85 & 0.42 & $31.29 * *$ \\
\hline H6 & 0.66 & 0.40 & $28.08 *$ \\
\hline H7 & 0.24 & 0.07 & $3.29 * * *$ \\
\hline H8 & 0.68 & 0.41 & $29.64 *$ \\
\hline H9 & 0.31 & 0.07 & $3.42 * * *$ \\
$*$ Significant at $\mathrm{P}<0.01 * *$ Significant at $\mathrm{P}<0.05 * * *$ Insignificant at $\mathrm{P}>0.05$ \\
\hline
\end{tabular}

Order of Entry to the Market

Hl: $1.26 / 0.47 / 0.01$

H5: 0.85/0.42/0.05

H8: $0.68 / 0.41 / 0.01$

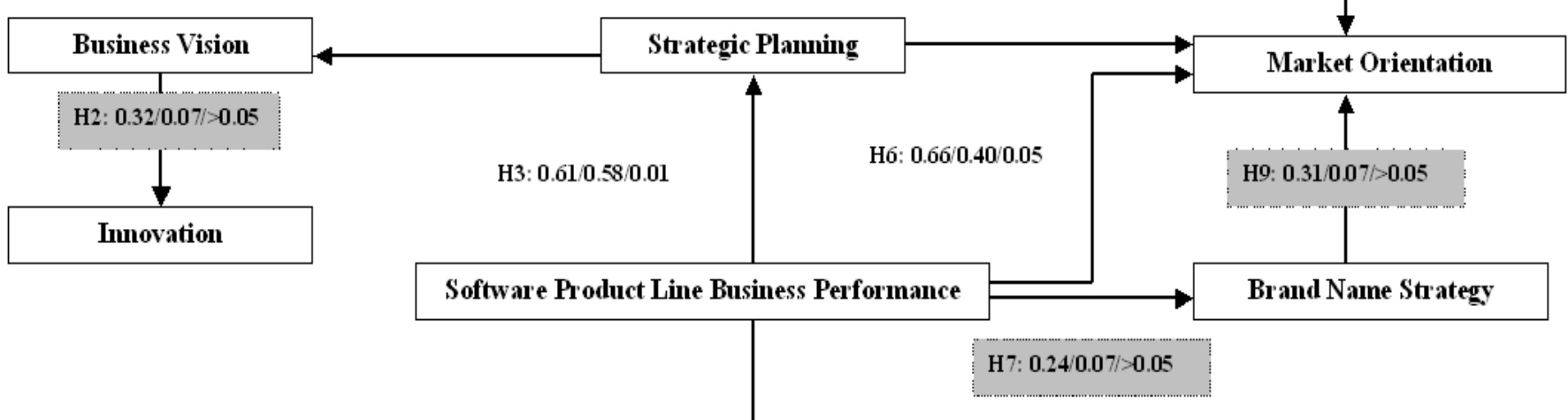

H4: $0.71 / 0.44 / 0.01$

Relationships Management

Figure 3: Structural Test of Research Model Using PLS Technique

\section{Sensitivity Analysis}

According Kitchenham et al. [30] in empirical investigations, it is important to perform a sensitivity analysis to understand how individual data points or clusters of data relate to the behavior of the whole collection. Saltelli et al. [39] define sensitivity analysis as the study of how the variation in the output of a model can be apportioned, qualitatively or quantitatively, among model inputs. We received varying number of respondents from different organizations. The minimum numbers of respondents from an organization were three and maximum were seven. The statistical analysis results reported in this paper are based on data received from all the respondents. This raised two major concerns on the sensitivity of the results of this study. First, the data of the organization having maximum (7) respondents may have a strong influence on the outcome of the study. Secondly, varying number of respondents within an organization may have conflicting opinions about the performance of software product line with in same organization. In order to address these two scenarios of data sensitivity on the overall outcome of the study, we conducted and reported here the sensitivity analysis of this investigation. First, we eliminated the data of the organization that has provided maximum number of responses i.e., 7 and performed the statistical analysis of all the hypotheses on the rest of the 
data. The purpose of this sensitivity analysis is to observe the change in the outcome of the study in the absence of the data of the organization that had maximum number of respondents by estimating a relative change in Pearson correlation coefficient and $\mathrm{R}^{2}$. The results of sensitivity analysis observed are reported in Table-V. We did not find any significant change in the outcome of the study in all the hypotheses except one. The outcome of hypothesis $\mathrm{H} 7$ (software product line performance and brand name strategy) has changed, which showed that there is a strong influence of the "brand name strategy" data of the organization having 7 respondents. In order to ensure the validity and to address the scenario where respondents within same organization may have conflicting opinion, we took an average score of each organization for all seven independent and the dependent variable and performed statistical analysis again. We did not find any considerable change on the overall outcome of the study, besides some changes in the statistical values especially in case of P-values. The overall findings of the study remained same in this situation.

\section{Table- V Sensitivity Analysis of the Study (After Eliminating Data of the Organization with 7-Responsdents)}

\begin{tabular}{|l|l|l|l|}
\hline Hypothesis & \multicolumn{1}{|c|}{$\begin{array}{c}\text { Change in } \mathrm{R}^{2} \\
(\%)\end{array}$} & $\begin{array}{c}\text { Change in Pearson } \\
\text { Correlation Coefficient } \\
(\%)\end{array}$ & Outcome of Study \\
\hline H1 & 8.50 & 6.06 & No Change \\
\hline H2 & 14.2 & 6.89 & No Change \\
\hline H3 & 1.72 & 1.29 & No Change \\
\hline H4 & 4.54 & 2.94 & No Change \\
\hline H5 & 27.6 & 17.7 & No Change \\
\hline H6 & 22.5 & 10.0 & No Change \\
\hline H7 & 42.8 & 25.0 & Change * \\
\hline H8 & 2.50 & 1.58 & No Change \\
\hline H9 & 28.75 & 12.5 & No Change \\
\hline
\end{tabular}

* P-Value is changed and now Significant at $\mathrm{P}<0.05$

\section{Discussion}

The concept of software product lines acquiesces to the influence of key business factors in successfully launching and maintaining a software product line business. Carrying out and managing the business of software product lines requires comprehensive knowledge of and expertise in key business factors, in addition to the desired level of excellence in software engineering. The key business factors highlighted as variables in this study characterize business processes and play a crucial role in managing a successful business in this changing, global economy.

\section{1) Hypotheses H1, $\mathrm{H3}$ and $\mathrm{H5}$}

Hypotheses $\mathrm{H} 1, \mathrm{H} 3$, and $\mathrm{H} 5$ involve strategic planning. In order to set clear objectives and align organizational resources to match opportunities and counter threats, software product line development requires serious consideration in organizational strategic planning. The positive association of business vision and strategic planning (H1) shows that the future direction of the business must consider software product lines as an integral asset. The positive association of the software product line business and strategic planning in hypothesis $\mathrm{H} 3$ emphasizes that the software product line process needs resources, which must be delegated in strategic plans. Strategic planning for software product lines ensures that decisions made to allocate and commit resources reflect the relative significance of the software product lines in achieving the long-range business goals. Hypothesis H5 supports the positive relationship between strategic planning and market orientation. Strategic planning, after having a comprehensive market orientation, must clearly outline what is to be developed from the software product line in order to gain competitive advantages and capture market segments to achieve strategic targets. Strategic plans are required to maintain organization-wide efforts to identify and exploit attractive long-range business opportunities by having software product lines in practice and capturing effective knowledge about the market.

\section{2) Hypotheses $\mathrm{H} 4$ and $\mathrm{H6}$}

Hypotheses $\mathrm{H} 4$ and $\mathrm{H} 6$ involve software product line business performance, relationships management, and market orientation. Software product lines deal with developing a considerable number of products to capture various market segments, thus providing justification for a product line. Market orientation provides imperative information about the concerns and 
requirements of customers, which need to be accommodated in successive products from a product line. Information regarding competitors is used to exploit product functionalities in order to attract new customers. Overall, the market orientation helps in creating a balance between product and customer centered approaches of the software product line development. The relationship between software product line business performance and market orientation is positively supported in hypothesis H6. Relationships management plays a significant role in successful software product line development, as supported by hypothesis H4. Customer orientation enables an organization to develop customer-centered products. This information assists in the domain- and application-engineering activities of the software product line development. Customers generally require assistance and training from the seller to successfully install software products and then use them effectively. Excellent customer support service enhances the customers' satisfaction with the products' functions. Also, customer profiling suggests new features in successive products from the software product line. Overall, close working relationships with customers allow the developers to improve the performance and functionalities of successive products from the product line.

\section{3) Hypothesis $\mathrm{H8}$}

Hypothesis $\mathrm{H} 8$ studies the effect of order of entry to the market on market orientation. Our study shows that there is a positive relationship between them. Appropriate timing to launch a software product into the market is essential for software development organizations. Traditionally, switching from an existing operational software system to a newer one is heavily based on the potential benefits and advantages that can be achieved. Organizations tend to rely on their current software if they do not perceive there will be a significant improvement in operational activities and technological advancements by switching to new software. Migration from a current system to a new, compatible system with enhanced functionalities is common practice in the software industry. Software product lines produce successive products with controlled variability and commonality. The new products from a software product line share the common software product line platform architecture and essentially have the basic features of their predecessors. Order of entry to the market is essential in launching a new product from a software product line in order to capture major shares of the market, and this cannot be achieved unless an organization conducts comprehensive market orientation exercises on a regular basis.

\section{4) Hypotheses $\mathrm{H2}$, H7, and $\mathrm{H9}$}

Hypotheses $\mathrm{H} 2, \mathrm{H} 7$, and $\mathrm{H} 9$ were not supported in this study. $\mathrm{H} 7$ and $\mathrm{H} 9$ involved brand name strategy, which is generally regarded as a core strategy in business literature. The idea of software product lines is a relatively new concept, and a lot of research and development in process definition and development methodology is in progress. Perhaps the software industry, in particular, has not yet understood and realized the significance of brand name strategy in doing business, with the exception of some large organizations. That is one of the main reasons that software product line business performance and brand name strategy did not show a significant relationship in this empirical investigation. Business vision does not support a positive relationship with innovation; the possible reason behind this again is the relative young age of the concept of software product families. Organizations are still struggling to institutionalize this concept because of the initial cost of setup and the long-term payback period.

\section{E. Limitations of the Study}

Certain limitations are the coherent feature of empirical investigations. Therefore, that is the case with this study. We used seven independent variables to relate with each other in some hypothesis and with the dependent variable of software product line business performance. There may be other business factors that influence the business performance of software product lines in addition to these seven. Some other contributing factors to business performance of software product lines, such as: organization size, economic and political conditions, are not considered in this study. We concentrated only on some of the key business factors. Although we used multiple respondents within the same organization to reduce bias, bias still is a core issue in decision-making. Software product lines are a relatively new concept in software development, and not many of the organizations in the software industry have institutionalized and launched this concept, so collecting data from the software industry was a limitation. We asked the respondents to consult major sources of data at their organization, i.e., documents, plans, models, and actors before responding to a particular item in order to reduce the human tendency to over- or under-estimate when filling in questionnaires. The items were designed using accepted psychometric principles, but the measurement is still largely based on the subjective assessment of an individual. Besides its general and specific limitations, this study contributes significantly in the area of software product lines and helps to understand the business dimension of software product lines. 


\section{CONClusion ANd Future Work}

Software product line is an inter-disciplinary concept, which has its roots in software engineering, business, management and organizational sciences. This research enables organizations to understand the effectiveness of the relationships and interdependency of business factors and software product lines. Our main objective was to empirically investigate the effect of business factors in the performance of software product lines thus finding answers to the research questions put forward in this investigation. The study conducted and reported here is a first of its kind in the area of software product lines. The summarized answers of the research questions are:

- The main objective of this study was finding the effect of business factors in the performance of software product line. This investigation confirms that business factors play a positive role in the performance of software product line, which reinforces the current perceptions of the significance of key business factors in successful software product line business. The results of this study provide evidence that organizations in the business of software product line development have to deal with multiple key business factors to improve the overall performance of the business, in addition to their efforts in software development. The organization needs to understand the business process of the product line, and the set of business factors must be aligned with software product line engineering process. Thus, there is a need to establish a strong coordination between business and engineering aspects of software product line.

- Strategic planning has an overall positive impact on the performance of software product line. This finding provides answer to second research question of this study. The initial cost of setting up and the long-term payback period entail a comprehensive strategic plan, which must be aligned with the organizational needs for initiating, launching and maintaining software product line. Strategic plans are required to maintain organization-wide efforts to identify and exploit attractive long-range business opportunities by having software product lines in practice and capturing effective knowledge about the market. The strategic plans should outline how an organization will achieve the technological capability to successfully adopt the concept of the software product line. It must specify the organizational goals and their inter-relationships with software product lines, along with the details of how the organization will accomplish them, including action plans and the financial, human, technological, and other resources required.

- Marketing strategy is one of the core area of concerns in business, this study reinforce that performance of software product line and marketing strategy has a positive association, thus providing answer to third research question. The orientation about market, competitors, and customers must be given a close attention in developing market plans. The organization must regularly conduct market reviews and updates the development and delivery schedule of the software product line. The organization should have an established defined inter-communication protocol among external and internal entities for the dissemination of market intelligence. Close working relationships with customers allow the developers to improve the performance and functionalities of successive products from the product line. Therefore organization must simplify business processes regularly to enhance customer experience and satisfaction.

Currently, we are working on developing a Process Maturity Model for process assessment of software product lines. The aim is to identify the Key Process Areas (KPA) of software product lines, along with specific and general practices carried out in each KPA. This work has provided the empirical justification to include these key business process factors in evaluating the business dimension of software product line process maturity.

\section{REFERENCES}

[1] R. S. Aguilar-Sav'en, Business process modeling: review and framework, International Journal of Production Economics 90 (2004) 129149.

[2] H. Ansoff, J. Stewart, Strategies for technology-based business, Harvard Business Review 43 (1967) 71-83.

[3] J. Bayer, O. Flege, P. Knauber, R. Laqua, D. Muthig, K. Schmid, T. Widen, J.M. DeBaud, PuLSE: a methodology to develop software product lines, in: Proceedings of the $5^{\text {th }}$ ACM SIGSOFT Symposium on Software Reusability, 1999, pp. 122-131.

[4] P.D. Bennett, Dictionary of marketing terms, American Marketing Association, 1988.

[5] A. Bergstrom, Cyber branding: leveraging your brand on the internet, Strategy and Leadership 28(4) (2000) 10-15.

[6] G. H Birk, John, I. Schmid, K. von der Massen T., Muller K., Product line engineering, the state of the practice, IEEE Software 20(6) (2003) 52-60. 
[7] G. Böckle, Innovation management for product line engineering organizations, in: Proceedings of the $9^{\text {th }}$ International Conference on Software Product Lines, 2005, pp. 124-134.

[8] G. Böckle, P. Clements, J. D. McGregor, D. Muthig, K. Schmid, Calculating ROI for software product lines, IEEE Software 21(3) (2004) 23-31.

[9] D.T. Campbell, D.W. Fiske, Convergent and discriminant validation by the multi-trait multi-method matrix, Psychological Bulletin 56(2) (1959) 81-105.

[10] R.B. Cattell, The scree tests for the number of factors, Multivariate Behavioral Research 1(1966) 245-276.

[11] P. Clements, On the importance of product line scope, in: Proceedings of the $4^{\text {th }}$ International Workshop on Software Product Family Engineering, 2001, pp. 69-77.

[12] P. Clements, and L.M. Northrop, Software product lines practices and pattern, Addison Wesley, 2002.

[13] J. Cohen, Statistical power analysis for the behavioral sciences, second ed. Hillsdale, N.J, 1988.

[14] A.L Comrey, and H.B. Lee, A first course on factor analysis, second ed. Hillsdale, N.J, 1992.

[15] L.J. Cronbach, Coefficient alpha and the internal consistency of tests, Psychometrica 16 (1951) 297-334.

[16] L.J Cronbach, Test validation, educational measurement, R.L. Thorndike, ed., second ed., Washington, 1971, pp. 443-507.

[17] L. Crosby, K. Evans, D. Cowles, Relationship quality in services selling: an interpersonal influence perspective, Journal of Marketing 54 (1990) 68-81.

[18] T.H. Davenport, Process innovation, Harvard Business School Press, Boston, MA, 1993.

[19] J. O. De Castro, J.J. Chrisman, Order of market entry, competitive strategy and financial performance, Journal of Business Research 33 (1995) 165-177.

[20] C. Ebert, M. Smouts, Tricks and traps of initiating a product line concept in existing products, in: Proceedings of the $25^{\text {th }}$ International Conference on Software Engineering, 2003, pp. 520-525.

[21] ESAPS Project Available from: http://www.esi.es/en/Projects/esaps/overview.html, 1996.

[22] C. Fornell, F. L. Bookstein, Two structural equation models: LISREL and PLS applied to consumer exit voice theory, Journal of Marketing Research 19(1982) 440-452.

[23] C. Fritsch, R. Hahn, Product line potential analysis, in: Proceedings of the $3^{\text {rd }}$ International Conference on Software Product Lines, 2004, pp. 228-237.

[24] E. F. Harrison, Strategic planning maturities, Management Decisions 33(2) (1995) 48-55.

[25] A. Jaaksi, Developing mobile browsers in a product line, IEEE Software 19(4) (2002) 73-80.

[26] K. Joreskog, H. Wold, Systems under indirect observation: causality, structure and prediction, North Holland, 1982.

[27] H.F. Kaiser, The application of electronic computers to factor analysis, Educational and Psychological Measurement 20 (1960) $141-151$.

[28] H.F. Kaiser, A second generation little jiffy, Psychometrika 35 (1970) 401-417.

[29] K.C. Kang, P. Donohoe, E. Koh, J. Lee, K. Lee, Using a marketing and product plan as a key driver for product line asset development, in: Proceedings of the 2nd International Conference on Software Product Lines, 2002, pp.366-382.

[30] B. A. Kitchenham, S. L. Pfleeger, L. M. Pickard, P. W. Jones, D. C. Hoaglin, K. El Emam, J. Rosenberg, Preliminary guidelines for empirical research in software engineering, IEEE Transactions on Software Engineering 28(8) (2002) 721-734.

[31] P. Knauber, D. Muthig, K. Schmid, T. Wide, Applying product line concepts in small and medium-sized companies, IEEE Software 17(5) (2000) 88-95.

[32] A. Kohli, B. Jaworski, Market orientation: the construct, research propositions, and managerial implications, Journal of Marketing 54 (1990) 1-18. 
[33] A. Martensen, J.J. Dahlgaard, Strategy and planning for innovation management, a business excellence approach, International Journal of Quality and Reliability Management 16(8) (1999) 734-755.

[34] J.C. Narver, S.F.Slater, The effect of a market orientation on business profitability, Journal of Marketing, 54 (1990) 20-35.

[35] E. Niemelä, Strategies of product family architecture development, in: Proceedings of the $9^{\text {th }}$ International Conference on Software Product Lines, 2005, pp. 186-197.

[36] J.C. Nunnally, I.A. Bernste, Psychometric theory, McGraw Hill, 1994.

[37] R.V. Ommering, Beyond Product Families: Building a product population, in: Proceedings of the Conference on Software Architectures for Product Families, 2000, pp.187-198.

[38] W. Robinson, C. Fornell, M. Sullivan, Are market pioneers intrinsically better than later entrants? Journal of Strategic Management 13 (1992) 609-624.

[39] A. Saltelli, K. Chan, M. Scott, Sensitivity analysis, probability and statistics series. John Wiley \& Sons: New York, NY, 2000.

[40] K. Schmid, M. Verlage, The economic impact of product line adoption and evolution, IEEE Software 9(4) (2002) 50-57.

[41] J. Stevens, Applied multivariate statistics for the social sciences, Hillsdale, NJ, 1986.

[42] D.W. Straub, Validating instruments in MIS research, MIS Quarterly 13(2) (1989) 147-169.

[43] B.Sutton, Long range planning in public libraries: staff perspectives, Library and Information Science Research, 15(4) (1993) $299-323$.

[44] P. Toft, D. Coleman, J. Ohta, A cooperative model for cross-divisional product development for a software product line, in: Proceedings of the $1^{\text {st }}$ International Conference on Software Product Lines, 2000, pp. 111-132.

[45] F. van der Linden J. Bosch, E., Kamsties, K. Känsälä, H. Obbink, Software product family evaluation, in: Proceedings of the $3^{\text {rd }}$ International Conference on Software Product Lines, 2004, pp. 110-129.

[46] F. van der Linden Software Product families in europe: the ESAPS \& Café projects, IEEE Software 19(4) (2002) $41-49$.

[47] T. Wappler, Remember the basics: key success factors for launching and institutionalizing a software product line, in: Proceedings of the $1^{\text {st }}$ Software Product Line Conference, 2000, pp. 73-84.

[48] J.G. Wijnstra, Critical factors for a successful platform-based product family approach, in: Proceedings of the $2^{\text {nd }}$ International Conference on Software Product Lines, 2002, pp. 68-89.

[49] D. T. Wilson, An integrated model of buyer-seller relationships, Journal of the Academy of Marketing Science 23 (1995) $335-345$.

\section{APPENDIX-I \\ Key Business Factors (Measuring Instrument)}

\section{Strategic Planning}

1. Organizational strategic planning places important consideration on software product lines.

2. Software product lines are aligned with organization's strategic plans.

3. Software product lines play a significant role in achieving the strategic objectives of the organization.

4. Organization's strategic plans define how it will achieve the technological capability to successfully adopt the concept of software product lines.

5. Strategic plans outline potential products for software product lines.

\section{Order of entry to the market}

6. Products developed from the software product line enter the market at the appropriate time.

7. The organization has the potential of being the first to introduce new products to the market.

8. The organization regularly conducts market reviews and updates the development and delivery schedule of the software product line, keeping market trends and needs in mind.

9. Software product line develops products in response to competitor actions. 
10. Successive products from the software product line help in retaining current customers and have a tendency to attract new customers.

\section{Brand Name Strategy}

11. Organization's software product line is unique or different from its competitors' products.

12. New products from the software product line are consistent with the brand extensions.

13. New products from the software product line attract the customers and considered as an extension or even an improved version of its predecessors.

14. Customers' decisions to buy are influenced by the brand name of the software product line.

15. The software product line has direct one-to-one competition in the market.

\section{$\underline{\text { Market Orientation }}$}

16. The organization uses customer's feedback to the improve quality of products and services.

17. The organization has adequate knowledge of customers and competitors.

18. The organization has adequate resources and skills to gather information about the market.

19. The organization successfully responds to the actions of competitors and eventually decreases the number of competitors.

20. The organization is able to increase market size, and there is a steady increase in market growth over time.

\section{Relationships Management}

21. The organization has fast and accurate means to access the required information to facilitate responses to customers' queries about products and services.

22. The organization has a well-established system to quickly extract, manipulate, and produce data for profitability analysis, customer profiling, and retention modeling.

23. The organization is able to retain customers over a long period of time.

24. The organization has established a balance in customer- and product-centered approaches to product development.

25. The organization attracts new and existing customers through personalized communication and innovative targeting methods.

\section{Business Vision}

26. The organization has a well-documented vision statement.

27. The business vision statement clearly communicates where the organization is going.

28. Software product lines play a significant role to achieve required business goals.

29. The business vision is regularly reviewed, updated as needed, and communicated to all in the organization.

30. A software product line is an integral part of the business vision.

\section{$\underline{\text { Innovation }}$}

31. The organization successfully employs innovations in its software product line development.

32. The innovations in the software product line are aligned with the existing business goals.

33. The management support reactive and proactive innovations in the software product line process.

34. The organizations' past innovative measures improve the development and management processes of the software product line.

35. The organization believes that investment in $R \& D$ can yield positive results in the near future.

\section{Software Product Line Business Performance}

1. Over the past five years, we have reduced the cost and development time of software products.

2. The sales of the organization have steadily increased over the last five years.

3. Customers are loyal to our organization and we have increased customers' satisfaction over the last five years.

4. Software product line has played a significant role in achieving the business goals of the organization.

5. Financial analysis shows a progressive growth over the last five years.

6. The brand name of our software product has an impact on purchasers' decisions.

7. Over the past five years we have significantly reduced the number of competitors. 
8. We are considered as pioneers in product development rather than followers in the industry.

\section{Appendix-II}

\section{(Key Business Factors Data)}

\begin{tabular}{|c|c|c|c|c|c|c|c|}
\hline $\begin{array}{l}\text { Strategic } \\
\text { Planning }\end{array}$ & $\begin{array}{c}\text { Order of Entry to } \\
\text { the Market }\end{array}$ & $\begin{array}{c}\text { Brand Name } \\
\text { Strategy }\end{array}$ & $\begin{array}{c}\text { Market } \\
\text { Orientation }\end{array}$ & $\begin{array}{l}\text { Relationships } \\
\text { Management }\end{array}$ & Business Vision & Innovation & \begin{tabular}{|c|} 
Software Product \\
Line \\
Performance
\end{tabular} \\
\hline 22 & 19 & 16 & 21 & 21 & 18 & 19 & 36 \\
\hline 21 & 18 & 16 & 22 & 20 & 19 & 20 & 34 \\
\hline 20 & 19 & 15 & 21 & 20 & 17 & 18 & 34 \\
\hline 22 & 19 & 15 & 23 & 20 & 18 & 19 & 35 \\
\hline 21 & 19 & 15 & 23 & 19 & 17 & 19 & 34 \\
\hline 20 & 16 & 13 & 15 & 17 & 19 & 18 & 32 \\
\hline 22 & 16 & 14 & 15 & 18 & 18 & 19 & 34 \\
\hline 18 & 17 & 14 & 14 & 17 & 19 & 18 & 33 \\
\hline 19 & 16 & 13 & 15 & 18 & 19 & 19 & 32 \\
\hline 21 & 16 & 12 & 15 & 17 & 20 & 20 & 32 \\
\hline 20 & 15 & 12 & 15 & 18 & 18 & 19 & 34 \\
\hline 20 & 15 & 14 & 15 & 16 & 18 & 19 & 34 \\
\hline 16 & 18 & 12 & 16 & 19 & 15 & 19 & 30 \\
\hline 17 & 18 & 12 & 16 & 19 & 13 & 18 & 31 \\
\hline 18 & 18 & 12 & 16 & 19 & 13 & 18 & 28 \\
\hline 17 & 17 & 12 & 15 & 18 & 15 & 17 & 30 \\
\hline 17 & 18 & 11 & 16 & 17 & 15 & 16 & 28 \\
\hline 11 & 13 & 13 & 13 & 12 & 14 & 18 & 26 \\
\hline 11 & 12 & 13 & 13 & 13 & 14 & 19 & 28 \\
\hline 10 & 12 & 13 & 12 & 12 & 15 & 17 & 27 \\
\hline 11 & 13 & 13 & 12 & 12 & 14 & 18 & 28 \\
\hline 11 & 12 & 12 & 13 & 13 & 16 & 17 & 26 \\
\hline 10 & 13 & 12 & 13 & 13 & 15 & 16 & 26 \\
\hline 11 & 12 & 13 & 12 & 12 & 16 & 18 & 28 \\
\hline 16 & 20 & 21 & 17 & 18 & 15 & 16 & 30 \\
\hline 17 & 21 & 21 & 16 & 19 & 16 & 16 & 32 \\
\hline 18 & 20 & 21 & 17 & 17 & 16 & 18 & 30 \\
\hline 17 & 20 & 22 & 16 & 18 & 15 & 17 & 32 \\
\hline 17 & 20 & 22 & 15 & 17 & 16 & 17 & 34 \\
\hline 16 & 21 & 21 & 17 & 17 & 16 & 18 & 30 \\
\hline 15 & 17 & 17 & 15 & 21 & 14 & 20 & 34 \\
\hline 14 & 17 & 16 & 17 & 20 & 14 & 22 & 34 \\
\hline 15 & 17 & 17 & 16 & 21 & 16 & 20 & 32 \\
\hline 15 & 16 & 17 & 17 & 19 & 16 & 20 & 34 \\
\hline 15 & 16 & 17 & 16 & 20 & 15 & 21 & 33 \\
\hline 20 & 19 & 16 & 19 & 21 & 17 & 18 & 36 \\
\hline 20 & 19 & 15 & 19 & 18 & 19 & 18 & 34 \\
\hline 20 & 20 & 16 & 19 & 18 & 19 & 19 & 36 \\
\hline 19 & 15 & 13 & 17 & 15 & 18 & 18 & 34 \\
\hline 20 & 18 & 13 & 15 & 16 & 18 & 23 & 35 \\
\hline 20 & 19 & 14 & 15 & 15 & 20 & 20 & 34 \\
\hline 21 & 19 & 13 & 15 & 16 & 18 & 21 & 32 \\
\hline 19 & 18 & 11 & 16 & 15 & 19 & 21 & 32 \\
\hline 20 & 18 & 11 & 17 & 16 & 16 & 22 & 32 \\
\hline
\end{tabular}

